\title{
FONTES DE AMIDO E TEMPERATURA DE ARMAZENAMENTO NA MANUTENÇÃO DA QUALIDADE PÓS-COLHEITA DA PITAYA DE POLPA VERMELHA
}

\author{
Alex Guimarães Sanches, Maryelle Barros da Silva, Elaine Gleice Silva Moreira, Carlos Alberto Martins \\ Cordeiro
}

Universidade Federal do Pará - UFPA, PA. E-mail: alexsanches.eng@gmail.com

\begin{abstract}
RESUMO
A pitaya (Hylocereus undatus (Haw) Briton \& Rose), é um fruto tropical que apresenta uma considerável perda pós-colheita devido a carência de técnicas que mantenham suas propriedades qualitativas durante o tempo de comercialização. Assim, a presente pesquisa objetivou avaliar o efeito de revestimentos naturais à base de amido associado ao armazenamento em diferentes temperaturas. 0 experimento foi conduzido em um delineamento inteiramente casualizado em arranjo fatorial $5 \times 4 \times 2$, sendo cinco tempos de avaliação, quatro tratamentos (sem revestimento, amido de arroz, amido de mandioca e amido de milho) e duas temperaturas de armazenamento $\left(10\right.$ e $\left.25^{\circ} \mathrm{C}\right)$, com quatro repetições e a parcela experimental composta por três frutos. A cada quatro dias as amostras aleatoriamente foram avaliadas quanto a perda de massa fresca, firmeza, sólidos solúveis, acidez titulável, pH, vitamina $\mathrm{C}$ e índice de maturação (SS/AT). Durante o armazenamento, observou-se que a qualidade dos frutos sofreu alterações quando armazenados sob temperatura de $25^{\circ} \mathrm{C}$. A utilização dos revestimentos a base de amido promoveu em ambas as temperaturas, o controle sobre as alterações fisiológicas que comprometem a qualidade dos frutos quando comparadas as amostras do tratamento controle. A vida útil das pitayas armazenadas a $10^{\circ} \mathrm{C}$ foi de até dezesseis dias sem diferenças significativas entre os tratamentos. Os revestimentos a base de amido de mandioca e amido de milho mostraram-se mais eficientes em manter a qualidade dos frutos quando armazenados a $25^{\circ} \mathrm{C}$ por até doze dias.
\end{abstract}

Palavras-chave: Fruta exótica; Hylocereus undatus (Haw) Briton\& Rose; polissacarídeos; revestimentos.

\section{STARCH SOURCES AND STORAGE TEMPERATURE IN POST-HARVEST QUALITY MAINTENANCE OF RED PULP PITAYA}

\begin{abstract}
The pitaya (Hylocereus undatus (Haw) Briton \& Rose) is tropical fruit that presents a considerable postharvest loss due to the lack of techniques that maintain its qualitative properties during the time of commercialization. Thus, the present study aimed to evaluate the effect of natural starch - based coatings associated with storage at different temperatures. The experiment was conducted in a completely randomized design in a $5 \times 4 \times 2$ factorial arrangement, five evaluation times, four treatments (uncoated, rice starch, cassava starch and corn starch) and two storage temperatures $\left(10\right.$ and $25^{\circ} \mathrm{C}$ ), with four replicates and the experimental plot composed by three fruits. Each day the samples were randomly evaluated for loss of fresh mass, firmness, soluble solids, titratable acidity, $\mathrm{pH}$, vitamin $\mathrm{C}$ and maturation index (SS / AT). During storage, it was observed that fruit quality changed when stored under $25^{\circ} \mathrm{C}$. The use of starch based coatings promoted control at both temperatures for physiological changes that compromise fruit quality when compared to control samples. The shelf life of pitayas stored at $10^{\circ} \mathrm{C}$ was up to sixteen days without significant differences between treatments. Cassava starch and corn starch coatings have been shown to be more efficient in maintaining fruit quality when stored at $25^{\circ} \mathrm{C}$ for up to twelve days.
\end{abstract}

Keywords: Exotic fruit; Hylocereus undatus (Haw) Briton \& Rose; polysaccharides; coatings. 


\section{INTRODUÇÃO}

A pitaya rosa de polpa vermelha também chamada apenas de "pitaya-vermelha" é uma planta rústica da família Cactaceae, originária da América (DONADIO, 2009). Trata-se de um fruto tropical, de aparência exótica, sabor doce e suave, polpa firme, e características nutricionais e funcionais que tornam seu cultivo considerado promissor (MARQUES et al.,2011).

Apesar do grande potencial econômico, a pitaya encontra-se entre as frutíferas pouco conhecidas, resultando em uma pequena literatura sobre o desenvolvimento, maturação e manuseio da fruta durante ou depois do armazenamento (FERNANDES et al., 2010). Desse modo, são necessárias pesquisas voltadas ao desenvolvimento de novas tecnologias para a redução das perdas pós-colheita, proporcionando assim, maior valorização comercial, atendendo as exigências de um mercado cada vez mais competitivo (VARGAS et al., 2008).

Dentre as diversas técnicas que, associadas ou não, favorecem o prolongamento de vida de prateleira de frutas, destaca-se o uso da refrigeração permitindo a redução de processos fisiológicos, o prolongamento da vida útil de produtos colhidos e o alcance de mercados mais distantes dos centros de produção (SAMIRA et al., 2011).

Atualmente, outra técnica que vem sendo estudada é o desenvolvimento de coberturas comestíveis protetoras (ASSIS; BRITO, 2014). Os revestimentos naturais a base de amido, classificados como polissacarídeos, possuem abundância de matéria-prima, pois podem ser extraídos de variadas fontes de cereais, raízes e tubérculos como o arroz, o trigo, o milho, a batata e a mandioca. Esses vegetais estão disponíveis em todo o mundo e apresentam diversas possibilidades de modificação química, física ou genética originando filmes e revestimentos resistentes (MÜLLER et al., 2008; MALI et al., 2010).

Com o intuito de explorar economicamente a pitaya visando a manutenção das características físico-químicas após a colheita, através de técnicas de conservação, o presente trabalho se propôs a avaliar diferentes fontes de amido como revestimento natural associado a condição de armazenamento sob diferentes temperaturas na sua qualidade pós-colheita.

\section{MATERIAL E MÉTODOS}

O presente trabalho foi conduzido no Laboratório de Biotecnologia do Centro de Estudos Ambientais- CEA, localizado no município de Altamira-PA em Novembro de 2015. Foram analisados frutos da variedade pitaya vermelha, com coloração de polpa vermelha, colhidas em estádio de maturação "de vez" em uma propriedade agrícola localizada município de Altamira-PA, sob as coordenadas geográficas 52은 $16^{\prime} 42,19^{\prime \prime}$ W e 3우 $10^{\prime} 0,82^{\prime \prime} \mathrm{S}$.

Os frutos foram colhidos nas primeiras horas da manhã, padronizados quanto ao tamanho, coloração da casca e ausência de defeitos fisiológicos e ou acometidos por pragas ou doenças. Estes foram acondicionados em caixas térmicas, contendo água e gelo, transportados até o laboratório onde foram lavadas em água corrente e posteriormente submetidos a sanitização em solução de cloro ativo a $5 \%$ por um período de três minutos. Logo após, foram dispostos em bancadas de alumínio previamente sanitizadas e secados manualmente.

Após a secagem, os frutos foram divididos em lotes e imersos em soluções com diferentes fontes de amido na concentração de $3 \%$ por um período de três minutos, sendo: amido de mandioca, amido de milho e amido de batata, além dos frutos que representaram o tratamento controle. Após os tratamentos, as pitayas foram acondicionadas em bandejas de isopor de poliestireno e mantidas em câmaras frias nas seguintes condições de temperatura, 10 e $25^{\circ} \mathrm{C}$ com $90 \%$ de umidade relativa do ar.

Para a obtenção das concentrações desejadas dos revestimentos, pesou-se $60 \mathrm{~g}$ de amido de arroz, 60g de amido de mandioca e $60 \mathrm{~g}$ de amido de milho, que foram diluídos em 2 litros de água destilada para cada suspensão, sendo ambas aquecidas à temperatura máxima de 70 으, com agitação constante, até geleificação da suspensão, o que ocorreu entre 5 e 10 minutos Após a obtenção da consistência, as suspensões permaneceram em repouso até resfriamento em temperatura ambiente.

O delineamento experimental adotado foi inteiramente casualizado em um arranjo fatorial $5 \times 4 \times 2$, sendo cinco tempos de avaliação $(0,4,8,12$ e 16 dias), quatro tratamentos (controle, amido de arroz, amido de mandioca e amido de milho) e duas temperaturas de armazenamento $\left(10\right.$ e $25^{\circ} \mathrm{C}$ ) com três repetições e a parcela experimental composta por três frutos. 
A cada tempo de armazenamento, avaliou-se: Perda de massa fresca, foi determinada com auxílio de uma balança semianalítica de precisão $0,01 \mathrm{~g}$, calculando-se a diferença de massa entre o início do experimento e após cada período de armazenamento, sendo os resultados expressos em porcentagem (\%). Avaliou-se a firmeza dos frutos (com casca) através de um penetrômetro marca TR, modelo FT 327, com ponteira de $8 \mathrm{~mm}$, na região equatorial em pontos equidistantes da fruta, dos dois lados, sendo os resultados expressos em Newton (N).

O conteúdo de sólidos solúveis foi mensurado por refratometria, utilizando-se uma gota da polpa da fruta macerada em refratômetro digital com conversão automática de temperatura e os resultados expressos em 'Brix, conforme metodologia descrita por Aoac (2012).

A acidez titulável foi quantificada por titulometria, através da titulação de $2 \mathrm{ml}$ de suco da polpa da fruta mais $20 \mathrm{ml}$ de água destilada com solução de $\mathrm{NaOH} 0,1 \mathrm{M}$ e como indicador a fenolftaleína a $1 \%$ baseando-se nas normas descritas pelo AOAC (2012), com os resultados sendo expressos em g de ácido cítrico/100g de polpa.

$\mathrm{O} \mathrm{pH}$ foi mensurado com auxílio de um potenciômetro digital modelo DMPH-2 Digimed através da imersão do eletrodo na polpa homogeneizada e diluída em $40 \mathrm{ml}$ de água destilada conforme preconizado por Aoac (2012).

O conteúdo de vitamina $C$ foi determinado pelo método proposto por Chen e
Wang (2002) em espectrofotômetro a 525 nm, sendo os resultados expressos na curva de calibração em g.100 $\mathrm{g}^{-1}$ de ácido ascórbico.

0 ratio SS/AT determinado pelo equilíbrio entre doce-ácido do produto durante o amadurecimento do fruto, foi calculada a relação entre sólidos solúveis e a acidez titulável (SS/AT). Os resultados foram expressos em número puro.

Os valores médios de cada variável foram submetidos à ANOVA e a análise de regressão, sendo aplicado o teste de Tukey ao nível de 5\% de probabilidade quando se verificou significância pelo teste $F$, através do software estatístico Assistat 7.7 versão beta.

\section{RESULTADOS E DISCUSSÃO}

A redução de massa fresca é decorrente de reações metabólicas, tais como, respiração e transpiração que promove a diminuição de água, murchamento e amolecimento dos tecidos, causando sérios danos à aparência e sabor do fruto, e a perda de massa fresca maiores que $5 \%$ são suficientes para depreciar a qualidade dos frutos e hortaliças (CARVALHO; LIMA, 2008).

Analisando a Figura 1, nota-se que houve efeito crescente da perda de massa fresca com o aumento do período de armazenamento dos frutos, contudo, observa-se que o acondicionamento dos frutos a $10^{\circ} \mathrm{C}$ permitiram perdas menos acentuadas com média de apenas $5,62 \%$ ao final de 16 dias. Para o mesmo período, os frutos mantidos a $25^{\circ} \mathrm{C}$ apresentaram percentual médio de $8,92 \%$.

Figura 1. Evolução da perda de massa fresca em pitayas revestidas ou não com biofilmes a base de amido:

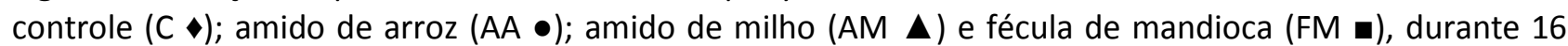
dias de armazenamento a 10 e a $25^{\circ} \mathrm{C}$.

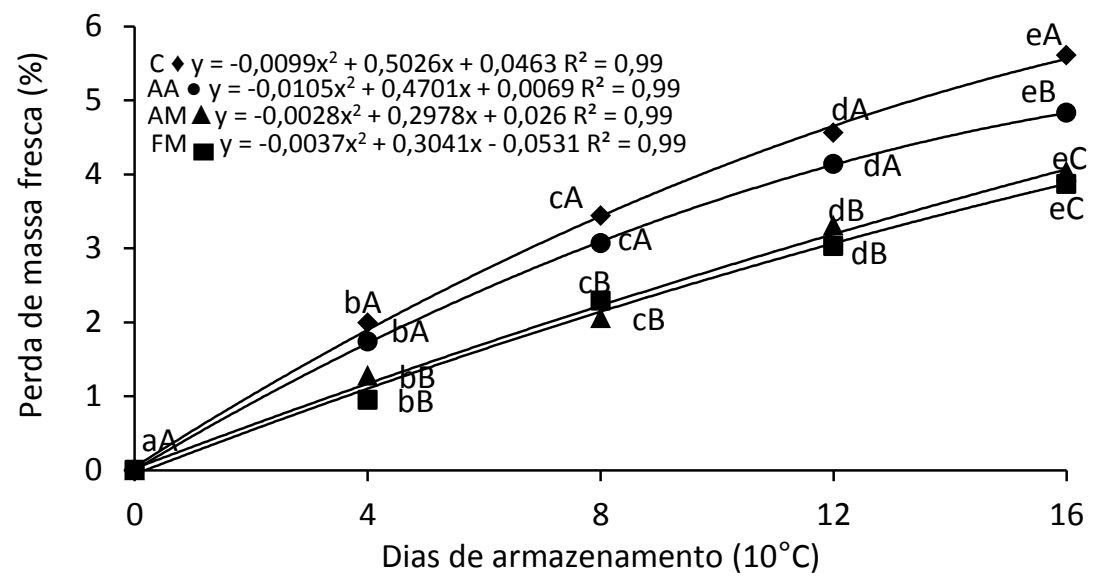




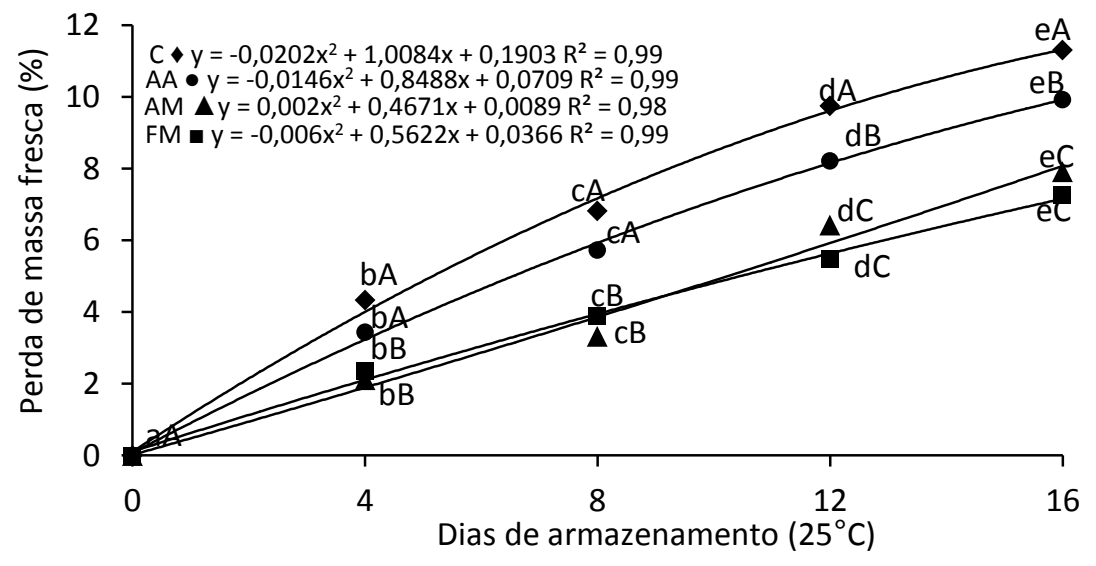

Tais resultados corroboram com os observados por Brunini e Cardoso (2011), que ao avaliarem diferentes temperaturas no armazenamento de pitayas de polpa branca, notaram que a condição de $8^{\circ} \mathrm{C}$ favoreceu perdas em torno de $5,72 \%$ com incremento na perda de massa fresca quando houve o aumento na condição de armazenamento para $25^{\circ} \mathrm{C}$ com percentual médio de $9,82 \%$.

Ainda de acordo com a Figura 1, observase que os frutos revestidos com biofilmes a base de fécula de mandioca e amido de milho não diferiram entre si nas diferentes condições de temperatura a qual foram armazenados, mostrando, portanto eficácia, em gerar uma barreira protetora sobre os frutos, reduzindo com isso as trocas gasosas e consequentemente a perda de água para o ambiente, com redução estimada em torno de $3,5 \%$ a $10^{\circ} \mathrm{C}$ e $5,8 \%$ a $25^{\circ} \mathrm{C}$.

Pego et al. (2015) e Santos et al. (2011), também verificaram efeito dos recobrimentos a base de fécula de mandioca e amido de milho no controle da perda de massa fresca em mamões e mangas, respectivamente.

Os percentuais médios verificados pelos frutos do tratamento controle não diferiram daqueles revestidos com amido de arroz para ambas as condições de armazenamento $\left(10^{\circ} \mathrm{C}\right.$ e $25^{\circ} \mathrm{C}$ ), atingindo perdas superiores a $4,7 \%$ e $8 \%$, respectivamente ao fim de 16 dias de armazenamento.

Analisando a Figura 2, observa-se que os frutos mantidos a temperatura de $10^{\circ} \mathrm{C}$ obtiveram um aumento na firmeza em todos os tratamentos, passando de $1,46 \mathrm{~N}$ no dia inicial para mais de $4,55 \mathrm{~N}$ ao final do período de avaliação. Os maiores valores de firmeza são registrados nos tratamentos controle e quando revestidos com amido de arroz, principalmente após o oitavo dia de análise.

Figura 2. Aumento na firmeza $(\mathrm{N})$ de pitayas revestidas ou não com biofilmes a base de amido: controle (C $\bullet$ ); amido de arroz (AA $\bullet$ ); amido de milho (AM $\mathbf{\Delta}$ ) e fécula de mandioca (FM $\mathbf{a})$, durante 16 dias de armazenamento a $10^{\circ} \mathrm{C}$.

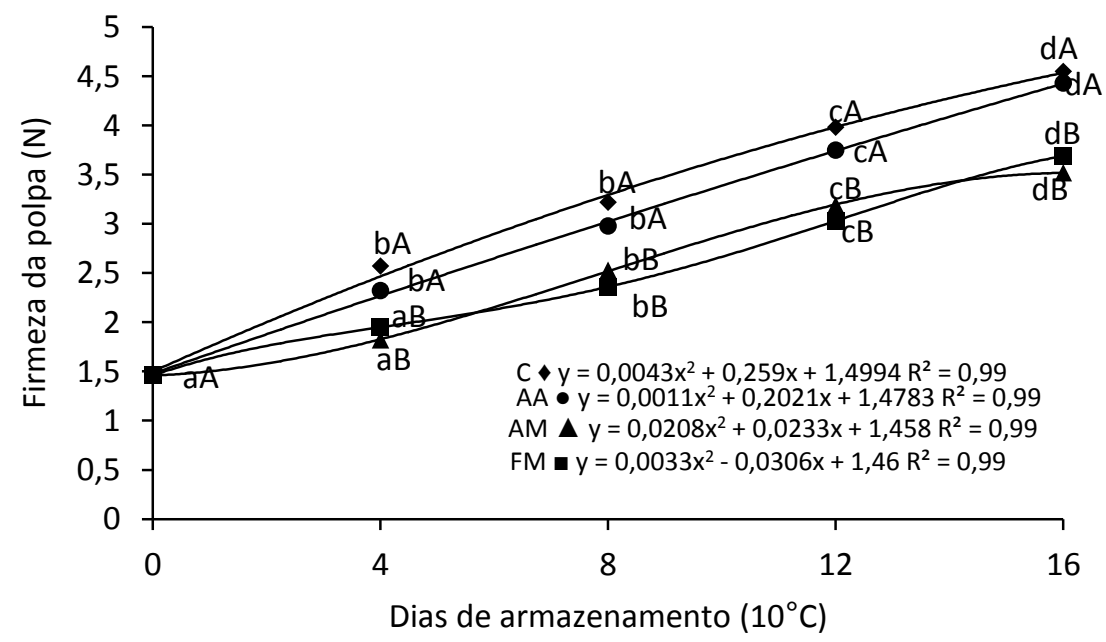


O acréscimo na firmeza dos frutos pode estar relacionado com a perda de massa fresca, que ocasiona murchamento e flacidez dos frutos tornando-os mais enrijecidos por conta da concentração de substâncias em sua polpa, e com isso, dificulta à penetração da ponteira do penetrômetro, como observado nos frutos dos tratamentos controle e quando revestidos com amido de arroz (Figura 2).

$O$ aumento progressivo na firmeza dos frutos neste estudo, é similar ao verificado por Wall e Khan (2008), que observaram maior firmeza em frutos de pitaya, durante armazenamento refrigerado a $8^{\circ} \mathrm{C}$, quando tratados com irradiação. Duarte et al. (2017), também verificaram pitayas mais firmes, passando de 1,5 para $4,0 \mathrm{~N}$, após 21 dias de armazenamento refrigerado a $13^{\circ} \mathrm{C}$.

No armazenamento dos frutos a temperatura de $25^{\circ} \mathrm{C}$, o comportamento da firmeza foi inverso, nota-se uma redução gradual nos valores médios com o tempo de armazenamento em todos os tratamentos (Figura 3).

Figura 3. Redução na firmeza ( $N$ ) de pitayas revestidas ou não com biofilmes a base de amido: controle (C $\bullet$ ); amido de arroz (AA •); amido de milho (AM $\mathbf{\Delta}$ ) e fécula de mandioca (FM $\mathbf{\bullet})$, durante 16 dias de armazenamento a $25^{\circ} \mathrm{C}$.

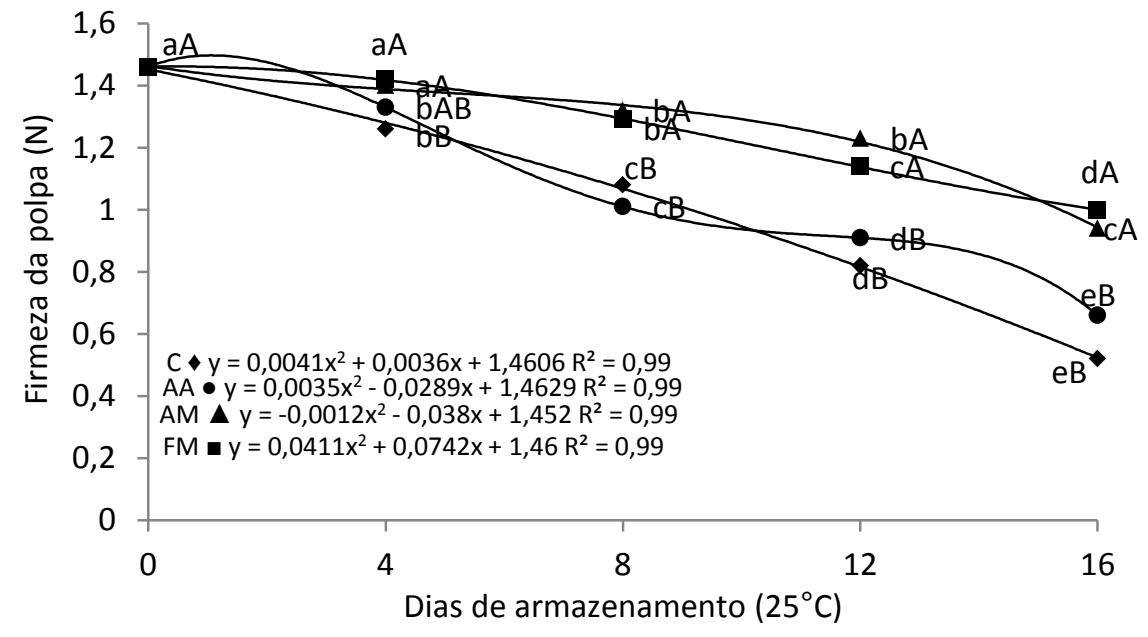

Esses resultados são similares aos verificados por Duenãs et al. (2009) e por Brunini e Cardoso (2011), que avaliando a qualidade de pitayas de polpa amarela e branca, respectivamente, reportam redução da firmeza quando mantidos à temperatura ambiente de $25^{\circ} \mathrm{C}$. Corroborando ainda com o relatado por Fernandes et al. (2010), que durante o armazenamento, a maioria dos frutos tendem a apresentar a diminuição da firmeza por conta do rompimento das paredes celulares por enzimas degradantes como a pectinametilesterase.

A ação dos revestimentos a base de fécula de mandioca e amido de milho apesar de não conterem a redução da firmeza, promoveram menores alterações diferindo significativamente dos tratamentos controle e com amido de arroz a partir do quarto dia de análise (Figura 3). O controle na redução de firmeza ocasionada por biofilmes a base de amido de milho e fécula de mandioca também foram relatados por Botrel et al. (2010) e Sarmento et al. (2015), em frutos como pêra e banana, respectivamente.

O teor de sólidos solúveis (SS) apresentou variações durante 0 período experimental influenciado tanto pelas condições de armazenamento $\left(10\right.$ e $25^{\circ} \mathrm{C}$ ) quanto pela ação dos revestimentos sobre sua superfície (Figuras 4 e 5).

Analisando o acondicionamento a $10^{\circ} \mathrm{C}$, nota-se que não houve alterações significativas entre os revestimentos e o tratamento controle até o quarto dia de análise com valores médios oscilando entre 11,8 a $12,3^{\circ}$ Brix (Figura 4). 
Figura 4. Variação no conteúdo de sólidos solúveis em pitayas revestidas ou não com biofilmes a base de amido: controle ( $C \bullet$ ); amido de arroz (AA $\bullet$ ); amido de milho (AM $\mathbf{\Delta}$ ) e fécula de mandioca (FM $\mathbf{\square}$ ), durante 16 dias de armazenamento a $10^{\circ} \mathrm{C}$.

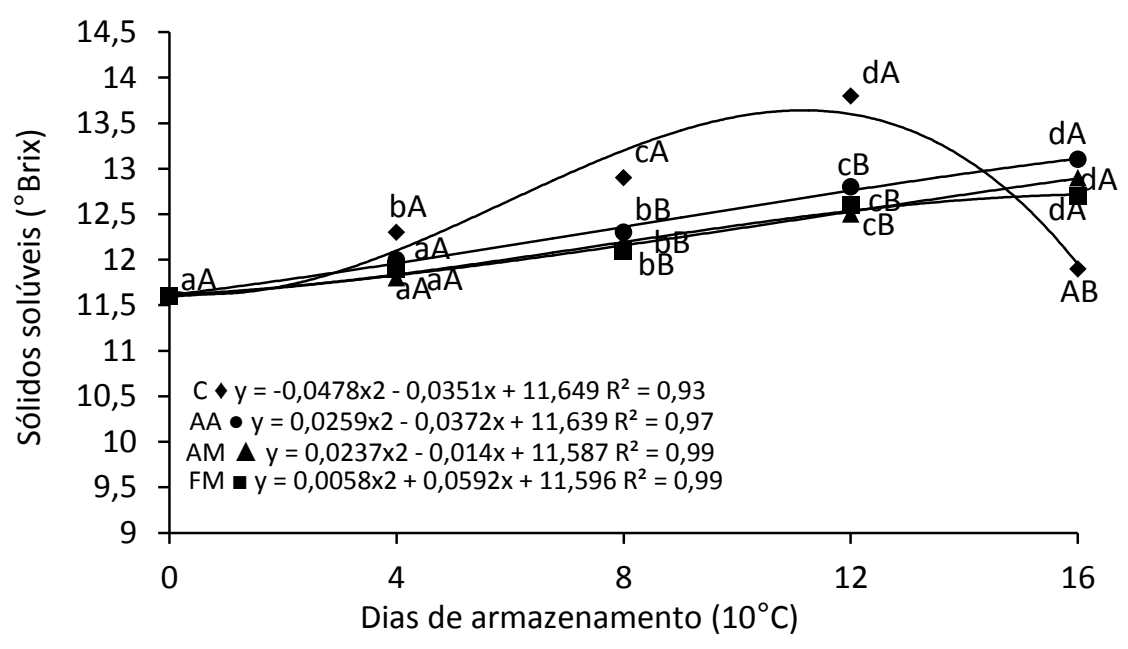

Entre o oitavo e $16^{\circ}$ dia de armazenamento, observa-se um acumulo mais acentuado de SS na polpa dos frutos revestidos não havendo diferença significativa quanto à fonte de amido utilizada, atingindo valores médios de $13,9^{\circ}$ Brix no último dia de avaliação. Nos frutos do tratamento controle, nota-se um acúmulo até $\mathrm{o} 12^{\circ}$ dia com valores médios de $13,8^{\circ} \mathrm{Brix}$, regredindo para $11,9^{\circ} \mathrm{Brix}$ no último dia de avaliação (Figura 4).
$\mathrm{O}$ acondicionamento dos frutos a $25^{\circ} \mathrm{C}$ promoveu alterações mais acentuadas quanto ao acúmulo de SS na polpa dos frutos. De modo geral, nota-se que os frutos do tratamento controle apresentaram um aumento expressivo até o quarto dia de avaliação quando apresentou média de $13,6^{\circ}$ Brix, com posterior regressão até o fim do armazenamento, com média inferior a $9,0^{\circ} \mathrm{Brix}$, diferindo significativamente dos demais tratamentos (Figura 5).

Figura 5. Variação no conteúdo de sólidos solúveis em pitayas revestidas ou não com biofilmes a base de amido: controle $(C \bullet)$; amido de arroz (AA $\bullet$ ); amido de milho (AM $\boldsymbol{\Delta}$ ) e fécula de mandioca (FM $\boldsymbol{\square}$ ), durante 16 dias de armazenamento a $25^{\circ} \mathrm{C}$.

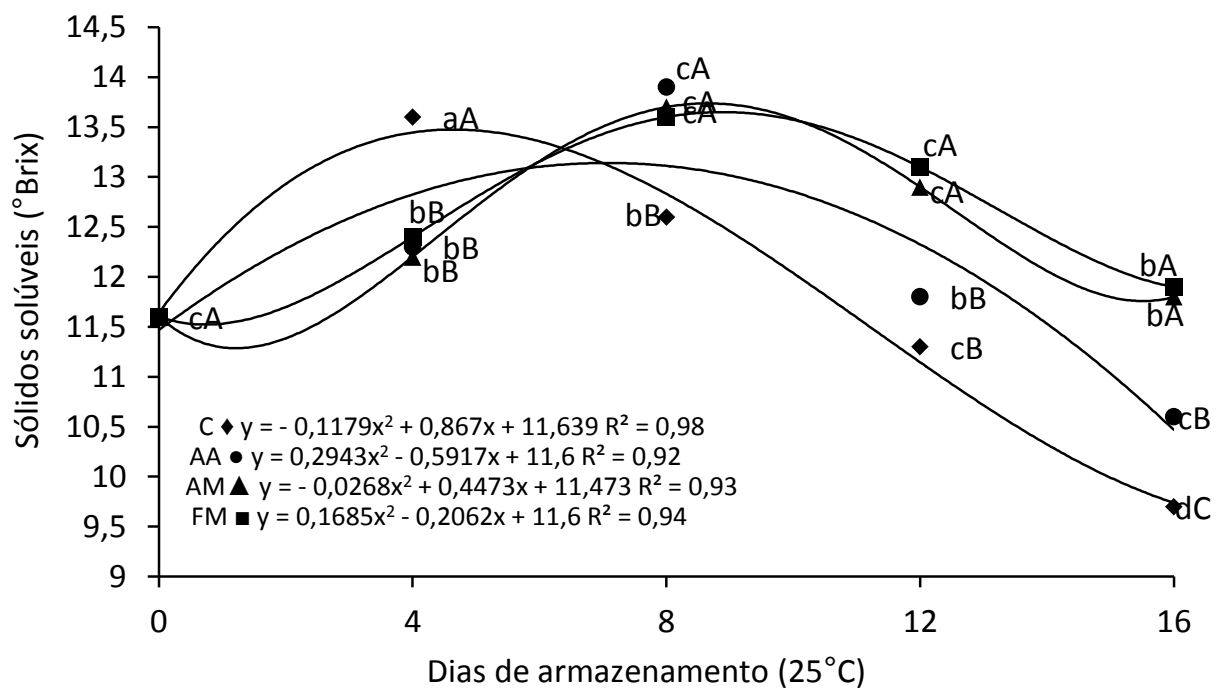

Os frutos revestidos com amido de arroz apresentaram ligeiros decréscimos ao final do armazenamento com média estimada de $10,2^{\circ}$ Brix, evidenciando dessa forma, que sua ação como película não foi eficiente na manutenção da atmosfera interna dos frutos, para garantir menor consumo dos SS como substrato no processo respiratório (Figura 5). Martins (2016), também não verificou eficiência do amido de arroz quando comparado a outros biofilmes sobre a conservação pós-colheita de uvas durante $o$ armazenamento por 15 dias. 
Nos frutos revestidos com fécula de mandioca e amido de milho também foram observadas reduções, contudo, estas foram menores, sugerindo controle sobre a atividade respiratória em função da menor síntese de SS (Figura 5). De maneira similar, Barbosa et al. (2012), também verificaram que as películas de amido de milho e fécula de mandioca reduziram a degradação dos SS na polpa de muricis, médias de 25,00 e $21,67^{\circ} \mathrm{Brix}$, respectivamente, quando comparado ao tratamento controle cuja média foi de $27,67^{\circ}$ Brix.

De acordo com as Figura 6 e 7, observa-se que os teores de acidez reduziram progressivamente independente do revestimento utilizado e da temperatura de armazenamento. Essa redução já era esperada em função do comportamento não climatérico do fruto, que sofre rápidas modificações fisiológicas após a colheita, e por isso utilizam em maior quantidade os ácidos orgânicos na atividade respiratória e na síntese de novos compostos visando manter a vida útil.

Decréscimos nos teores de acidez durante o armazenamento de pitayas também foram observados nos estudos de qualidade póscolheita dessa fruta por Wanitchang et al. (2010), cujos valores reduziram de 1,23 para 0,10 \% ácido cítrico e por Brunini e Cardoso (2011), onde os valores médios passaram de 1,42 para 0,21 \% ácido cítrico ao final de 25 dias.

Quando os frutos foram armazenados a $10^{\circ} \mathrm{C}$, observa-se que a redução é mais pronunciada somente após o oitavo dia de armazenamento. Ao final de 16 dias o conteúdo de acidez na polpa dos frutos do tratamento controle e quando revestidos com amido de arroz corresponderam aos menores valores 0,18 e 0,21 $\%$ ácido málico/100 g, respectivamente (Figura 6).

Figura 6. Redução da acidez em pitayas revestidas ou não com biofilmes a base de amido: controle ( $C$ ); amido de arroz (AA •); amido de milho (AM $\boldsymbol{\Delta}$ ) e fécula de mandioca (FM $\mathbf{a})$, durante 16 dias de armazenamento a $10^{\circ} \mathrm{C}$.

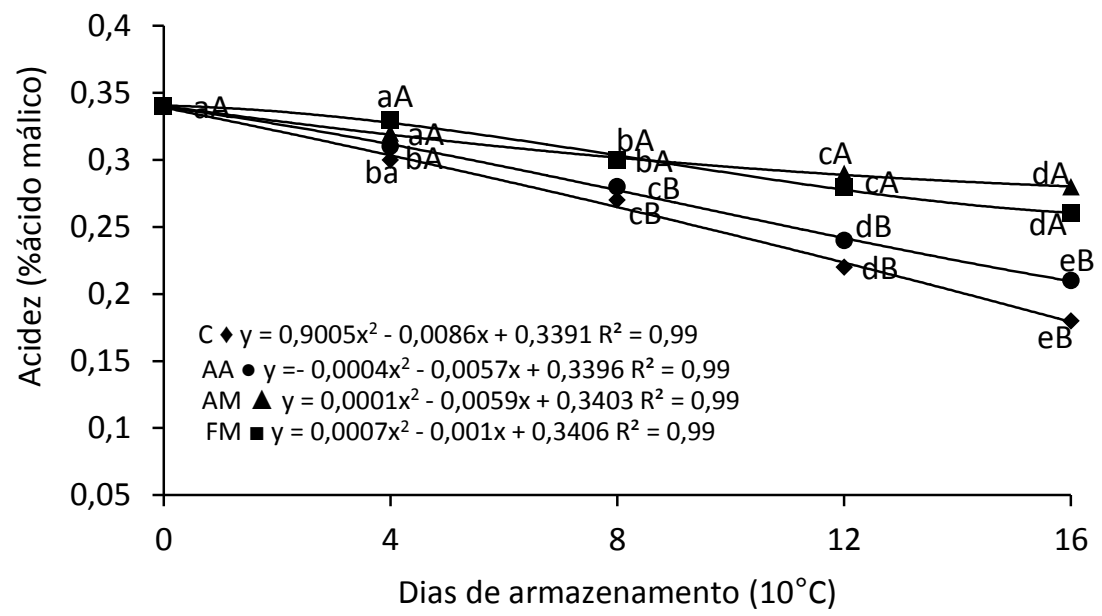

Os frutos revestidos com fécula de mandioca e amido de milho não diferiram entre si, e foram estatisticamente superiores aos demais tratamentos por apresentarem reduções menos expressivas de acidez durante 0 armazenamento das pitayas, com médias no último dia de avaliação em torno de 0,26 \% ácido málico (Figura 6).
Para o armazenamento a $25^{\circ} \mathrm{C}$ a redução foi expressiva logo após o quarto dia de análise quando os teores observados foram de 0,21; 0,23; 0,27 e $0,29 \%$ de ácido málico para os tratamentos controle, amido de arroz, amido de milho e fécula de mandioca, respectivamente (Figura 7). 
Figura 7. Redução da acidez em pitayas revestidas ou não com biofilmes a base de amido: controle (C $\downarrow$ ); amido de arroz (AA •); amido de milho (AM $\mathbf{\Delta}$ ) e fécula de mandioca (FM $\mathbf{a})$, durante 16 dias de armazenamento a $25^{\circ} \mathrm{C}$.

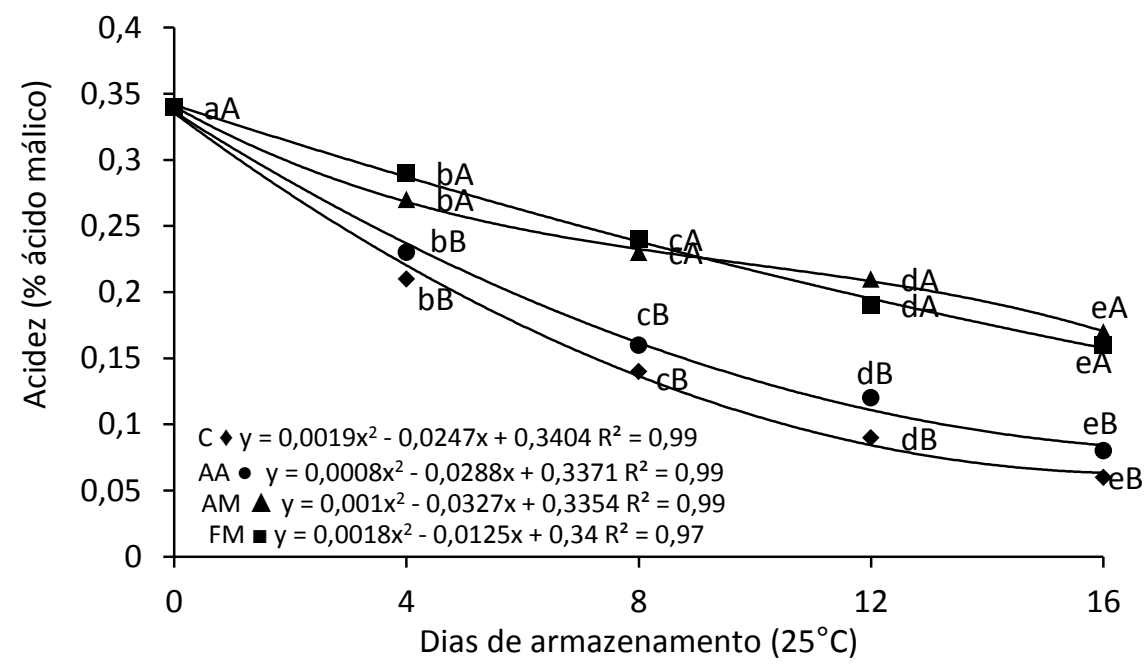

Palharini et al. (2015), verificaram que o armazenamento de amora preta em temperaturas baixas promove reduções menos drásticas nos teores de acidez na polpa dos frutos, condicionando assim um atraso no processo de amadurecimento, fato este similar ao verificado nesta pesquisa onde 0 acondicionamento dos frutos a $10^{\circ} \mathrm{C}$ inibiu a degradação dos ácidos orgânicos com o tempo de armazenamento, possivelmente pelo maior controle sobre a atividade respiratória dos frutos.

Não houve diferenças significativas entre os tratamentos controle e amido de arroz com médias inferiores a $1 \%$ ao final de doze dias de armazenamento (Figura 7). Para Duarte et al. (2017), teores de acidez inferiores a $1 \%$ é um bom indicativo de sabor e doçura na polpa de pitayas, condicionando um estádio mais avançado de maturação dos frutos.

$O$ revestimento com fécula de mandioca e amido de milho não diferiram no último dia de avaliação apresentando teores médios de 0,14 e
0,17 \% de ácido málico na polpa dos frutos, respectivamente (Figura 7 ).

O menor consumo dos ácidos orgânicos nos frutos revestidos com amido de mandioca e amido de milho nas condições de 10 e $25^{\circ} \mathrm{C}$, provavelmente está associado à eficiência da película protetora que os envolveu, controlando as principais reações metabólicas que envolvem a respiração, o amadurecimento e a senescência das pitayas. A utilização do revestimento a base de amido de milho promoveu poucas alterações nos teores de acidez na polpa de muricis (Barbosa et al., 2012), assim como na polpa de bananas prata revestidas com amido de mandioca (Sarmento et al., 2015).

$\mathrm{O}$ acondicionamento das pitayas a 10 e a $25^{\circ} \mathrm{C}$ promoveram um aumento linear nos valores de $\mathrm{pH}$ com o passar do tempo de armazenamento, independente da utilização ou não do revestimento (Figura 8). 
Figura 8. Aumento do $\mathrm{pH}$ em pitayas revestidas ou não com biofilmes a base de amido: controle (C $\downarrow$ ); amido de arroz (AA •); amido de milho (AM $\mathbf{\Delta}$ ) e fécula de mandioca (FM $\mathbf{m}$ ), durante 16 dias de armazenamento a 10 e a $25^{\circ} \mathrm{C}$.
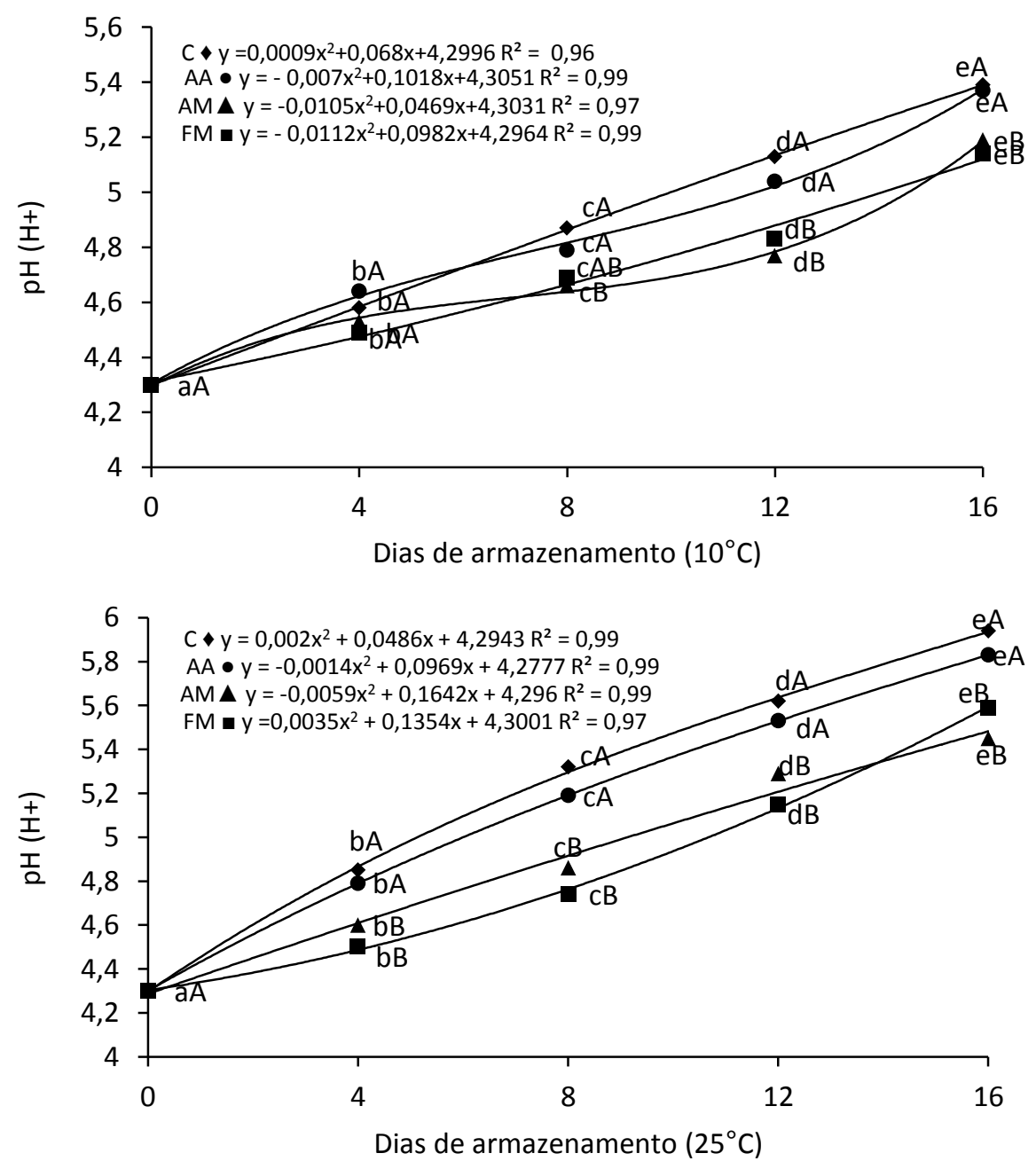

O armazenamento das pitayas a temperatura de $10^{\circ} \mathrm{C}$ apresentou um incremento de $\mathrm{pH}$ variando entre 4,3 no dia zero para valores em torno de 5,35 ao final de 16 dias. Quando mantidas na condição de $25^{\circ} \mathrm{C}$, nota-se um aumento gradual com o passar dos dias atingindo valores médios ao final do experimento entre 5,45 a 5,88 (Figura 8 ).

Os valores de $\mathrm{pH}$ observados nesta pesquisa estão dentro da faixa verificada por Silva e Alves (2009), que ao avaliarem a composição físico-química da polpa do mandacaru, uma espécie de cactácea, observaram valores iniciais de $\mathrm{pH}$ em torno de 4,5. Brunini e Cardoso (2011), trabalhando com pitayas de polpa branca encontraram valores oscilando entre 4,6 a 5,8 ao longo de vinte dias de armazenamento refrigerado. Duarte et al. (2017), ao avaliar pitayas de polpa vermelha durante 21 dias de armazenamento refrigerado verificou valores entre 4,3 a 5,6.
A utilização dos revestimentos a base de fécula de mandioca e amido de milho promoveram um maior controle sobre as alterações do $\mathrm{pH}$ até o $12^{\circ}$ dia quando mantidos a $10^{\circ} \mathrm{C}$ cuja média foi de $4,95 \mathrm{pH}$, e até o oitavo dia quando os frutos mantiveram-se a temperatura de $25^{\circ} \mathrm{C}$, média de $4,85 \mathrm{pH}$, diferindo estatisticamente dos demais tratamentos (Figura 8).

$$
\text { O tratamento controle favoreceu as }
$$
maiores alterações independente da temperatura de armazenamento, contudo, quando os frutos mantiveram-se expostos à temperatura de $25^{\circ} \mathrm{C}$, não foi observada diferença significativa quando comparado aos frutos revestidos com amido de arroz (Figura 8).

Os teores de vitamina C apresentaram comportamentos diferenciados no decorrer do tempo de avaliação, com médias oscilando entre 29,09 a 34,93 mg de ácido ascórbico/100 g. polpa, sendo esta variação influenciada tanto 
pela temperatura de armazenamento $\left(10\right.$ e $\left.25^{\circ} \mathrm{C}\right)$, quanto ao efeito promovido pelos revestimentos a base de amido (Figuras 9 e 10).

Brunini e Cardoso (2011), encontraram valores médios durante o armazenamento em diferentes temperaturas de pitayas oscilando entre 28,19 e 32,38 mg de ácido ascórbico/100 g. polpa, valores estes dentro da faixa verificada neste trabalho, durante o tempo de armazenamento.
Nos frutos revestidos com diferentes fontes de amido e armazenados a $10^{\circ} \mathrm{C}$, nota-se valores crescentes até o fim do armazenamento passando de 29,09 mg de ácido ascórbico/100 g. polpa no dia zero para mais de $34,0 \mathrm{mg}$ de ácido ascórbico/100 g. polpa ao final e 16 dias, não apresentando diferenças entre si (Figura 9).

Figura 9. Teor de vitamina $C$ em pitayas revestidas ou não com biofilmes a base de amido: controle (C $\downarrow$ ); amido de arroz (AA •); amido de milho (AM $\boldsymbol{\Delta}$ ) e fécula de mandioca (FM $\mathbf{a})$, durante 16 dias de armazenamento a $10^{\circ} \mathrm{C}$.

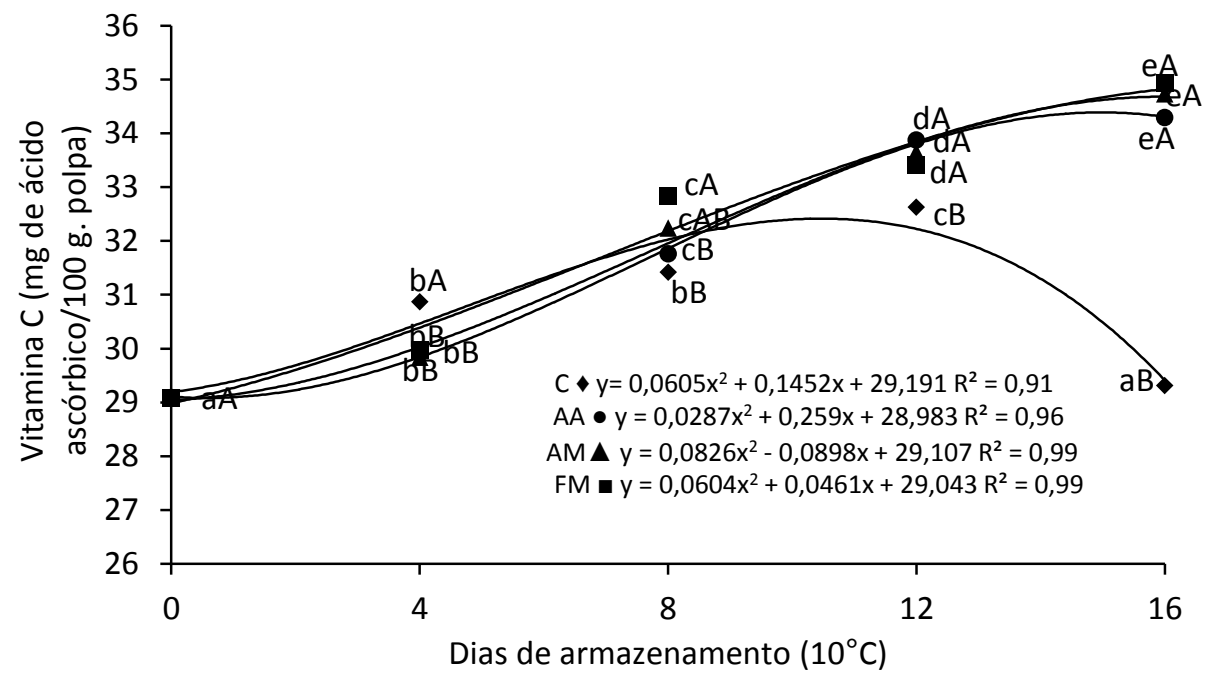

Os frutos do tratamento controle apresentaram aumento nos valores de vitamina $C$ somente até $012^{\circ}$ quando o teor médio observado foi de $32,6 \mathrm{mg}$ de ácido ascórbico/100 g. polpa. A partir de então, nota-se uma redução gradual atingindo teores próximos aos identificados no dia zero de avaliação (Figura 9).

Ferreira et al. (2010), citam que o aumento gradativo do teor de vitamina $\mathrm{C}$ durante o amadurecimento de frutos é reflexo da translocação contínua e síntese da enzima precursora da vitamina C (L-ascórbico), que durante a maturação e a condição de armazenamento pode aumentar ou manter-se estável por conta do acúmulo de sólidos solúveis e açúcares redutores não utilizados no metabolismo do amadurecimento dos frutos.

Para o armazenamento a $25^{\circ} \mathrm{C}$, houve a degradação da vitamina $C$ logo após quatro dias nos frutos do tratamento controle quando o teor verificado foi de $33,9 \mathrm{mg}$ de ácido ascórbico/100 g. polpa, e após oito dias quando revestidos com diferentes fontes de amido cujas médias oscilaram entre 32,6 a $33,8 \mathrm{mg}$ de ácido ascórbico/100 g. polpa (Figura 10). 
Figura 10. Teor de vitamina $C$ em pitayas revestidas ou não com biofilmes a base de amido: controle ( $C \downarrow$ ); amido de arroz (AA •); amido de milho (AM $\mathbf{\Delta}$ ) e fécula de mandioca (FM $\mathbf{m})$, durante 16 dias de armazenamento a $25^{\circ} \mathrm{C}$.

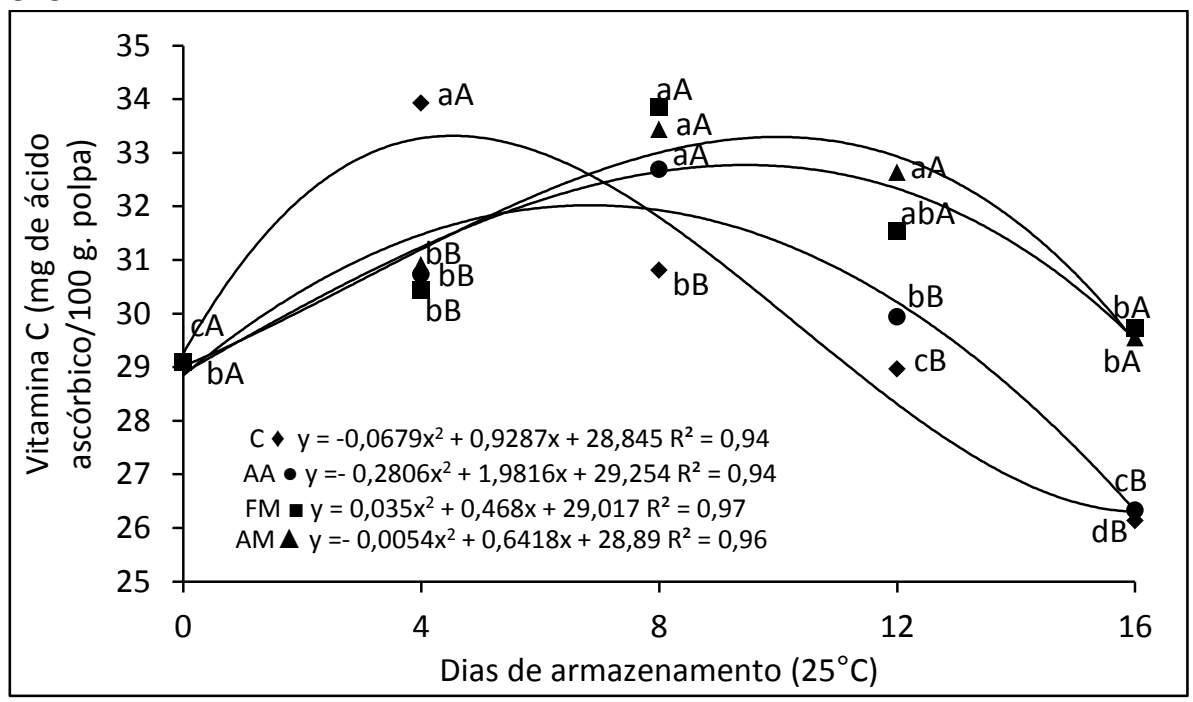

No período final de armazenamento, os teores médios de vitamina $\mathrm{C}$ dos frutos revestidos com fécula de mandioca $(29,72 \mathrm{mg}$ de ácido ascórbico/100 g. polpa) e amido de milho (29,55 mg de ácido ascórbico/100 g. polpa), foram significativamente maiores quando comparados aos frutos revestidos com amido de arroz e controle cujas médias corresponderam a 26,3 e 26,1 mg de ácido ascórbico/100 g. polpa, respectivamente (Figura 10).

Assim, a barreira gerada pelo biofilme de fécula de mandioca e amido de milho apresentam-se como alternativas ao controle das reações de biossíntese da vitamina $C$ que levam a sua degradação durante 0 período de armazenamento.
O índice de maturação, definido pela relação entre SS/AT é um importante parâmetro de avaliação da qualidade dos frutos, pois expressa a boa relação entre os sólidos solúveis (açúcares) e a acidez titulável (ácidos) presentes na polpa dos frutos, sendo utilizado como indicador do estágio de maturação (CHITARRA; CHITARRA, 2005). Assim, quanto maior essa relação, maior será sua maturação e melhor seu sabor pelo balanço entre o doce e o ácido.

De acordo com a Figura 11, observa-se que a relação SS/AT aumentou ao longo do tempo de armazenamento nos frutos armazenados a $10^{\circ} \mathrm{C}$, independente do uso ou não de revestimento. Os valores de modo geral oscilaram entre 38,43 no dia inicial e atingiram valores superiores a 85,00 ao final de 16 dias.

Figura 11. Índice de maturação (SS/AT) em pitayas revestidas ou não com biofilmes a base de amido: controle (C $\bullet$ ); amido de arroz (AA $\bullet$ ); amido de milho (AM $\mathbf{\Delta}$ ) e fécula de mandioca (FM $\mathbf{m}$ ), durante 16 dias de armazenamento a $10^{\circ} \mathrm{C}$.

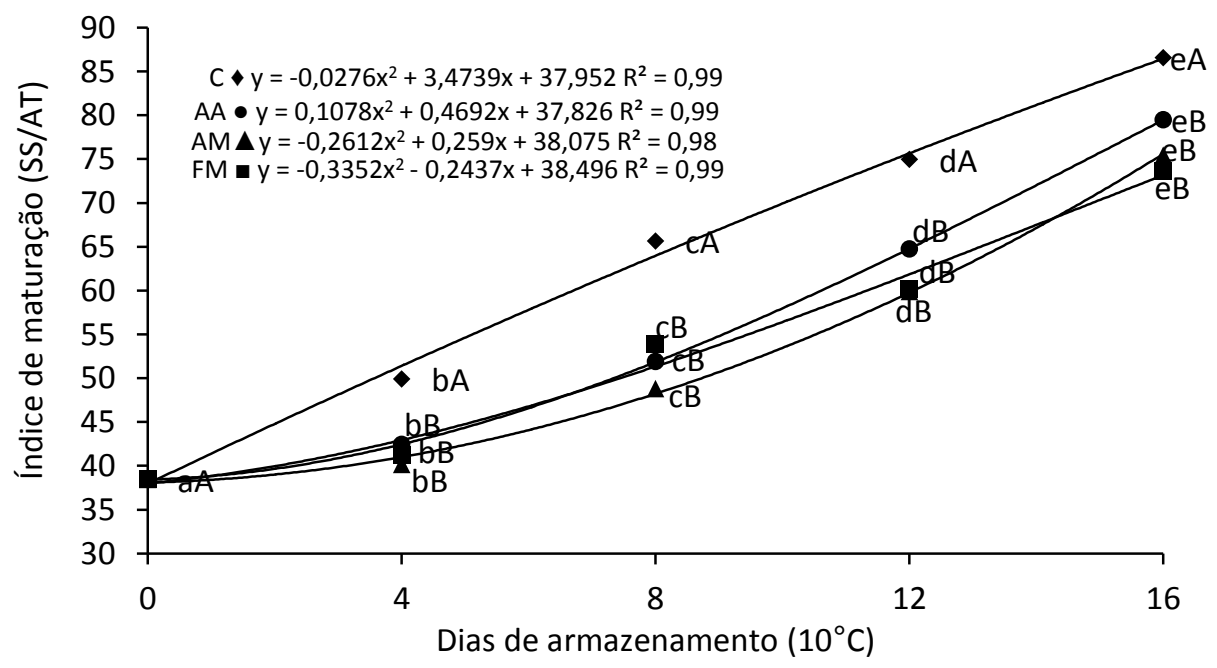


Estes resultados estão dentro da faixa determinada por Duarte et al. (2017), que encontraram variações na relação de SS/AT entre 40,00 a 90,00 durante 21 dias armazenamento refrigerado a $13^{\circ} \mathrm{C}$ de pitayas submetidas a adubação orgânica.

De maneira geral, pode-se observar que o revestimento utilizado retardou o aumento de SS/AT quando comparado aos frutos do tratamento controle durante os 16 dias de armazenamento, tal fato relaciona-se com a capacidade protetora gerada pelos biofilmes capaz de regular as trocas gasosas com o ambiente de forma mais amena, favorecendo um atraso no amadurecimento dos frutos (Figura 11).

$\mathrm{O}$ armazenamento das pitayas a $25^{\circ} \mathrm{C}$ provocou variações no comportamento da relação SS/AT com o tempo de armazenamento, nota-se que nos frutos do tratamento controle a um aumento expressivo até o oitavo dia quando apresentaram média de 83,21 , e a partir de então os valores decrescem até 0 fim do armazenamento com médias inferiores a 55,00 (Figura 12).

Figura 12. Índice de maturação (SS/AT) em pitayas revestidas ou não com biofilmes a base de amido: controle $(C \bullet)$; amido de arroz (AA $\bullet$ ); amido de milho (AM $\boldsymbol{\Delta}$ ) e fécula de mandioca (FM $\mathbf{m}$ ), durante 16 dias de armazenamento a $25^{\circ} \mathrm{C}$.

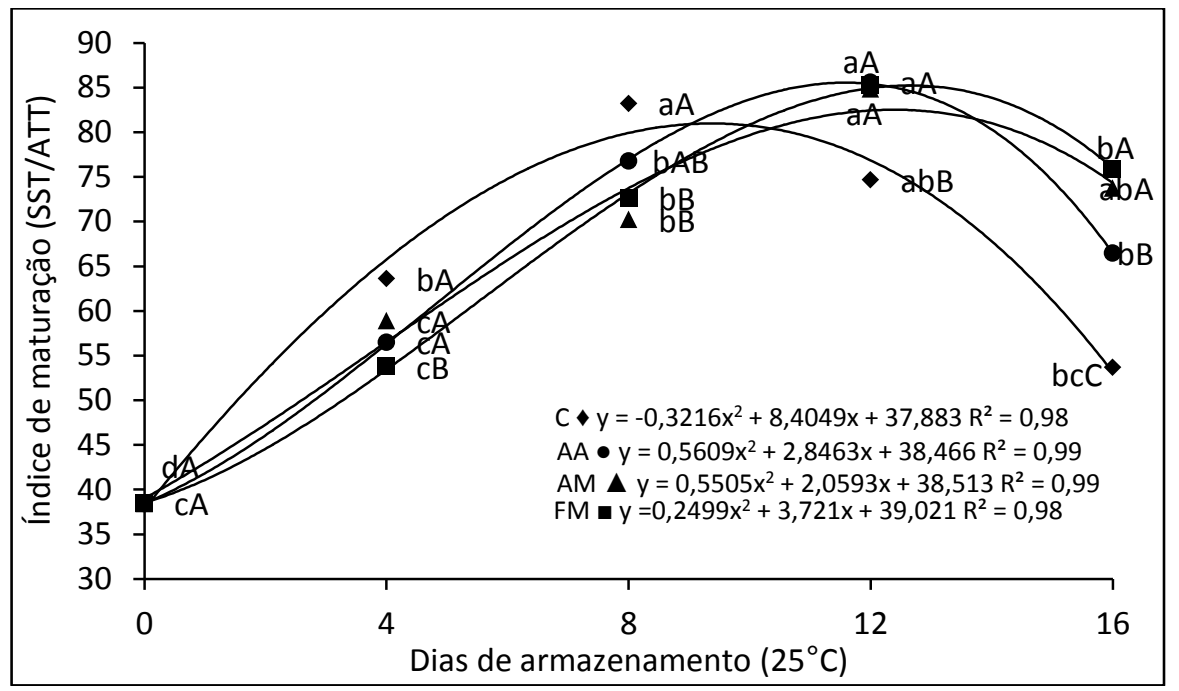

Nos frutos revestidos com diferentes fontes de amido, não foram observadas diferenças significativas entre si até o $12^{\circ}$ dia de avaliação, quando as médias para os tratamentos amido de arroz, amido de mandioca e amido de milho corresponderam a $85,56,85,78$ e 84,81 , respectivamente. Após este período, notam-se reduções na relação SS/AT com maior expressividade nos frutos revestidos com amido de arroz, verificando médias ao fim do armazenamento oscilando entre 66,44 a 75,00 entre os revestimentos (Figura 12).

Um dos fatores que podem justificar essa queda nas médias para a temperatura ambiente é a aparência de desordens fisiológicas decorrentes do amadurecimento como o início do apodrecimento dos frutos, tornando-os com um sabor menos desejável pelos consumidores.

\section{CONCLUSÕES}

A qualidade das pitayas está condicionada a 16 dias quando armazenada a $10^{\circ} \mathrm{C}$, associando-se aos revestimentos a base de amido.

Quando armazenadas em condições de temperatura ambiente $\left(25^{\circ} \mathrm{C}\right)$, a vida útil chega a 12 dias, especialmente quando os frutos são revestidos com amido de mandioca e amido de milho.

A qualidade dos frutos mantidos a $10^{\circ} \mathrm{Ce}$ a $25^{\circ} \mathrm{C}$ sem o uso de revestimentos é limitada a 12 e 8 dias, respectivamente.

\section{REFERÊNCIAS}

AOAC - Association of Official Analytical Chemistry. Official methods of analysis of the Association of Official Analytical Chemistry. Washington: AOAC, 2012. 
ASSIS, O. B. G.; BRITO, D. de. Revisão: coberturas comestíveis protetoras em frutas: fundamentos e aplicações. Brazilian Journal Food Technology, Campinas, v.17, n.2, p.87-97, 2014. http://dx.doi.org/10.1590/bjft.2014.0199.

BARBOSA, G. M.; SANCHES, C. L. G.; COSTA, R. de. Q.; VIRGENS, V. A. S. das.; NASCICMENTO, R. S. M. Películas comestíveis na conservação póscolheita de Murici. Enciclopédia Biosfera, Centro Científico Conhecer, Goiânia, v.8, n.15, p. 12791287, 2012.

BOTREL, D. A.; SOARES, N. de. F. F.; CAMILLOTO, G. P.; FERNANDES, R. V. de. B. Revestimento ativo de amido na conservação pós-colheita de pera Williams minimamente processada. Ciência Rural, Santa Maria, v.40, n.8, p.1814-1820, 2010. http://dx.doi.org/10.1590/S0103-

847820100008000233.

BRUNINI, M. A.; CARDOSO, S, S. Qualidade de pitaias de polpa branca armazenadas em diferentes temperaturas. Revista Caatinga, Mossoró, v. 24, n. 3, p. 78-84, 2011.

CARVALHO, A.V.; LIMA, L.C.O. Modificação de componentes da parede celular e enzimas de kiwis minimamente processados submetidos ao tratamento com ácido ascórbico, cítrico e $\mathrm{CaCl}_{2}$. Revista Brasileira de Fruticultura, Jaboticabal, v.22, n.3, p.386-390, 2008. https://doi.org/10.1590/S0100$\underline{29452010000200008}$

CHITARRA, M. I. F.; CHITARRA, A. B. Pós-colheita de frutas e hortaliças: fisiologia e manuseio. 2. ed. Lavras: UFLA, 2005. 785 p.

CHEN, J.; WANG, X. experimental instruction of plant physiology. South Chima University of Tecnology Press, Guangzhou, p. 124, 2002.

DUARTE, M. H.; QUEIROS, E. R.; ROCHA, D. A.; COSTA, A. C.; ABREU, C. M. P. de. Qualidade de pitaia (Hylocereus undatus) submetida à adubação orgânica e armazenada sob refrigeração. Braz. J. Food Technol., Campinas, v.20, $\quad$ n.2, p.1-11, 2017. https://doi.org/10.1590/1981-6723.11515.

DUENÃS, Y. M.; NARVÁREZ, C. E. C.; RESTREPO, L. P. S. El choque térmico meljoralaaptitud al almacenamiento refrigerado de pitaya amarilla.
Agronomia Colombiana, Bogota, COL, v. 27, n. 1, p. 105-110, 2009.

DONADIO, L. C. Pitaya. Revista Brasileira de Fruticultura, Jaboticabal, v.31, n.3, p. 637-929, 2009.

FERNANDES, L. M. S.; VIEITES, R. L.; CERQUEIRA, R. C.; BRAGA, C. L.; SIRTOLI, L. F.; AMARAL, J. L. Características pós-colheita em frutos de pitaya orgânica submetida a diferentes doses de irradiação. Revista Biodiversidade, Rondonópolis, v. 9, n. 1, p. 15-22, 2010.

FERNANDES, D. F. O.;AROUCHA, E. M. M.; SOUZA, P. A. de.; SOUSA, A. E. D. de.; FERNANDES, P. L. de. O. Qualidade demamão "Formosa" produzido no RN e armazenado sob atmosfera passiva. Revista Ciência Agronômica, Fortaleza, v. 41, n. 4 p. $\quad$ 599-604, 2010. https://doi.org/10.1590/S180666902010000400012.

FERREIRA, S. M. R., FREITAS, R. J. S. D., KARKLE, E. N. L., QUADROS, D. A. D., TULLIO, L. T., LIMA, J. J. D. Qualidade do tomate de mesa cultivado nos sistemas convencional e orgânico. Ciência e Tecnologia de Alimentos, Lavras, v. 30, n.1, p. 224-230, 2010. http://dx.doi.org/10.1590/S0102053620130004000200

MALI, S.; GROSSMANN, M. V. E.; YAMASHITA, F. Filmes de amido: produção, propriedades e potencial de utilização. Semina: Ciências Agrárias, Londrina, v. 31, n. 1, p. 137-156, 2010. DOI: http://dx.doi.org/10.5433/1679-

0359.2010v31n1p1377

MARQUES, V. B.; MOREIRA, R. A.; RAMOS, J. D.; ARAÚJO, N. A.; SILVA, F. O. R. Fenologia reprodutiva de pitaya-vermelha no município de Lavras-MG. Ciência Rural, Santa Maria, v. 41, n.6, p.984-987, 2011. https://doi.org/10.1590/S010384782011005000071

MARTINS. P. A. Cobertura comestível composta à base de amido de arroz nativo e extrato etanólico de folhas de carambola na conservação pós-colheita de uvas benitaka, 2016, 80 f. Dissertação (Mestrado) - Instituto Federal do Triângulo Mineiro, Uberaba, 2016.

MÜLLER; C. M. O., YAMASHITA, F; LAURINDO, J. $B$. Evaluation of the effects of glycerol and 
sorbitol concentration and water activity on the water barrier properties of cassava starch films through a solubility approach. Carbohydrate Polymers, Barking, v. 72, n. 1, p. 82-87, 2008. https://doi.org/10.1016/i.carbpol.2007.07.026.

PALHARINI, M. C. de. A.; FISCHER, I. H.; VEGIAN, M. R. da. C.; FILETI, M. de S.; MONTES, S. M. N. M. Efeito da temperatura de armazenamento na conservação pós-colheita de amora-preta. Pesq. Agropec. Trop., Goiânia, v. 45, n. 4, p. 413-419, 2015. https://doi.org/10.1590/198340632015v4537752

PEGO, J. N.; AMBRÓSIO, M.; NASCIMENTO, D. S.; FACHI, L. R.; KRAUSE, W. Conservação póscolheita de mamão 'sunrise solo' com revestimento comestível a base de fécula de mandioca. Enciclopédia Biosfera, Centro Científico Conhecer, Goiânia, v.11 n.21, p. 628639, 2015.

SAMIRA, A.; WOLDETSADIK, K.; WORKNEH, T. S. Postharvest quality and shelf life of some hot pepper varieties. Journal of Food Science and Technology, Mysore, v. 50, n. 5, p. 842-855, 2011. https://doi.org/10.1007/s13197-011-04051 .

SANTOS, L. O.; MARTINS, R. M.; DURIGAN, J. F.; MATTIUZ, B. Técnicas de conservação póscolheita do morango em refrigeração. Informe Agropecuário, Belo Horizonte, v. 28, n. 236, p. 84-87, 2007.

SANTOS, A. E. O.; ASSIS, J. S.; SANTOS, O. O.; BATISTA, G. G. Influência de biofilmes de fécula de mandioca e amido de milho na qualidade póscolheita de mangas 'Tommy Atkins'. Rev. Bras. Ciênc. Agrár, Recife, v.6, n.3, p.508-513, 2011. https://doi.org/10.5039/agraria.v6i3a755

SARMENTO, D. H. A.; SOUZA, A. P.; SARMENTO, J. D. A.; FREITAS, R. V. S.; SALGADO FILHO, M. Armazenamento de banana 'prata catarina' sob temperatura Ambiente recobertas com fécula de mandioca e pvc. Revista Caatinga, Mossoró, v. 28, n. 2, p. 235-241, 2015.

SILVA, L. R.; ALVES, R. E. Caracterização físicoquímica de frutos de mandacaru. Revista Acadêmica de Ciências Agrárias e Ambiente, Curitiba, v. 7, n. 2, p. 199-205, 2009.
VARGAS, M.; PASTOR, C.; CHIRALT, A.; MCCLEMENTS, D. J.; GONZÁLEZMARTÍNEZ, C. Recent advances in edible coatings for fresh and minimally processed fruits. Food Science and Nutrition, Boca Raton, v. 48, n. 6, p. 496-511, 2008.

https://doi.org/10.1080/10408390701537344.

WALL, M. M.; KHAN, S. Postharvest quality of dragon fruit (Hylocereus spp.) after X-ray irradiation quarantine treatment. Hort Science, Alexandria, v. 43, n. 7, p. 2115-2119, 2008.

WANITCHANG, J.; ANUPUM, T.; WANITCHANG, P.; NOYPITAC, S. Maturity indezod dragon fruit: Hyloceresus polyerhizus. Journal of Food Engineering, Thailand, v. 100, n. 3, p. 409-416, 2010.

https://doi.org/10.1016/i.jfoodeng.2010.04.025.

Recebido para publicação em 30/04/2017

Revisado em 19/09/2017

Aceito em 09/10/2017 